\title{
Zu hohe Erwartungen
}

Liebe Leserin, lieber Leser,

Erwartungsmanagement, das ist ein neues Stichwort, mit dem Stephan Wolfsried für eine realistischere Einschätzung der verantwortlichen Umsetzung von hochautomatisierten Fahrfunktionen wirbt. Auf der 1. Internationalen ATZ-Fahrerassistenztagung - von der Assistenz zum automatisierten Fahren“ Ende April bremste der Leiter Fahrzeugfunktionen und Fahrwerk bei Daimler die überzogenen Erwartungen an das automatisierte Fahren. „Nicht nur die Gesetzgebung, sondern auch unser Anspruch an die funktionale Sicherheit wird das automatisierte Fahren begrenzen“, machte Wolfsried deutlich.

Bisher entschleunigten Rechts- und Security-Experten die sich zum Hype entwickelten Ankündigungen und Pläne der Fahrzeugindustrie. Daimler und Audi präsentierten noch im Januar auf der Consumer Electronics Show (CES) in Las Vegas öffentlichkeitswirksame Fahrten im Modus der Vollautomatisierung. Jetzt kann man von einer Kehrtwende in der Kommunikation sprechen.

Die Kehrtwende bedeutet hoffentlich auch, so äußern Automobilexperten, dass die deutschen OEMs dem symbolträchtigen (scheinbar) autonom fahrenden Google Car nicht mehr nacheifern, sondern mit der gebotenen Vorsicht bei technischen Entwicklungen gegenhalten.

Lässt sich aus solchen Korrekturphasen lernen? Beispielsweise der Gartner Hype Cycle zeichnet die errechenbar durchlaufenen Entwicklungen eines Hypes auf. Das in der öffentlichen Wahrnehmung zum Greifen nahe autonome Fahren befindet sich Expertenmeinungen zufolge nach dem Wellenkamm der überzogenen Erwartungen bereits im Abschwung, nahe des „Tals der Tränen“. Die Kurve bewegt sich dann weniger steil nach oben, um sich anschließend auf einem stetig flachen Anstieg einzupendeln.
Doch das Tal der Tränen ist noch nicht erreicht. Welche Dämpfer sind noch zu erwarten? Immer deutlicher wird, dass im Fall des hochautomatisierten Fahrens die Haftung des Kunden sukzessive in die Produkthaftung des OEM übergeht. Der Fahrzeugentwickler haftet nicht nur, sondern er muss beispielsweise bei der Programmierung eines automatisierten Ausweichassistenten über Leben und Tod unterschiedlicher Verkehrsteilnehmer und des Fahrers entscheiden. Algorithmus des Todes, so nennen es Rechtsexperten. Das dämpft den Enthusiasmus.

Die Ernüchterung ist in der Politik allerdings noch nicht angekommen, während in Ingenieurskreisen kritisch beäugt wird, welche Zeichen Ministerien heute setzen. Der Teilabschnitt der A9 als Teststrecke fürs autonome Fahren sei praxisfremd. Letzendlich könnte sogar das hochautomatisierte Fahren noch auf der Strecke bleiben. Denn der Fahrer muss nach heutigem Stand der Diskussionen die Kontrolle über sein Fahrzeug jederzeit sicherstellen, und das noch jenseits 2030.

Herzliche Grüße

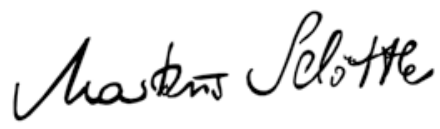

Markus Schöttle

Stellvertretender Chefredakteur Wiesbaden, 12. Mai 2015

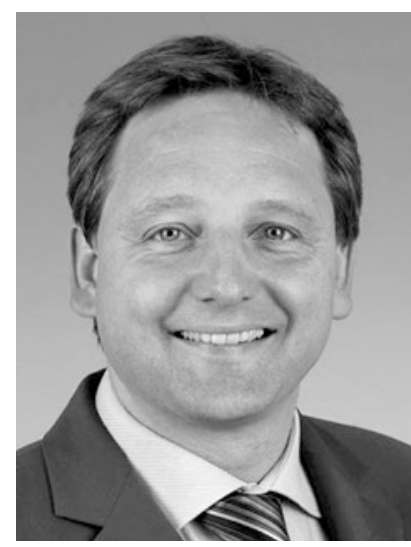

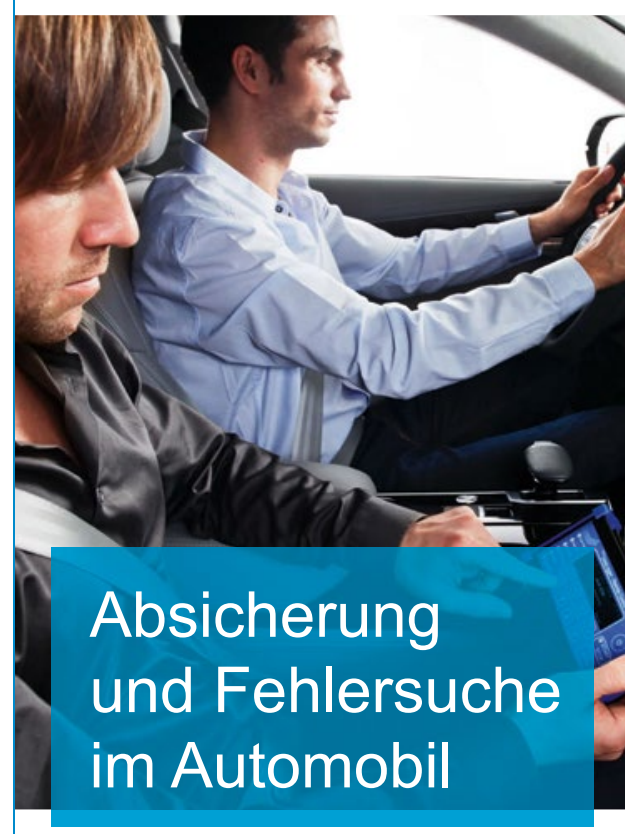

TTXDataLogger

- Ganzheitliche Datenerfassung aller Busse mit zentralem Zeitstempel

- Powermanagement mit neuem Super Sleep Modus $<100 \mu \mathrm{A}$

- Online Datenvisualisierung via WLAN

- Trigger, Filter und Klassierung der Signale
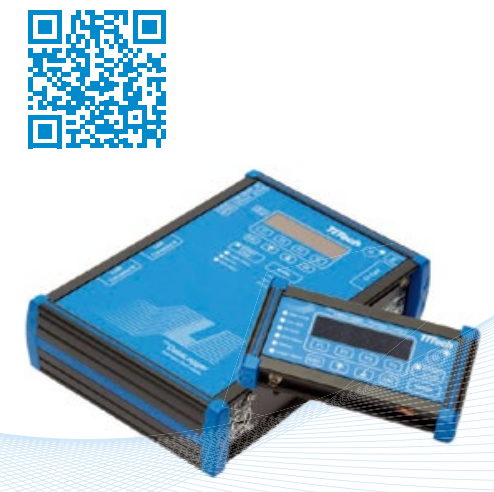

products@tttech-automotive.com

www.ttech.com/ logger 